\title{
Are Free Maternity Services in Kenya really free?
}

\author{
Micah Matiang'i* \\ School of Public Health-Jomo Kenyatta University of Agriculture and Technology, Nairobi, Kenya.
}

Received: January 25, 2018; Accepted: March 19, 2018; Published: March 20, 2018

*Corresponding author: Micah Matiang'i, School of Public Health-Jomo Kenyatta University of Agriculture and Technology, Kisumu, Kenya; Tel: +254-723727-325; E-mail:- miconyiego@gmail.com

\section{Introduction}

In developing countries where inequalities to health care are common, providing universal access to health care for all women is important to reduce birth related complications. Evidence shows that poor outcomes for mothers and babies during the perinatal period - the few weeks immediately before and after birth are linked to limited use of skilled care in health facilities. Among the barriers to using skilled birth attendance services in developing countries is the cost of care [1]. In June 2013, Kenya introduced a free maternity care policy to improve on the poor maternal and neonatal health outcomes that were being experienced. At that time, Kenya's maternal mortality rate was 488 per 100,000 live births compared to developed countries such as Switzerland which by then had a maternal mortality rate of 5 per 100,000 live births [2].

This policy was meant to enable Kenya increase use of health facility based services by mothers, achieve national development goals (Vision 2030) and global health development targets (SDGs 3,5 and 10). However, this policy was implemented oblivious of other factors that also directly affect pregnancy outcomes such as the number of health care workers available, availability of supplies and equipment, access to quality of health education in health facilities. At the time of policy implementation, the staffing ratios in facilities stood at 159 nurses for every 100,000 population and 21 doctors for every 100,000 population [2].

Although the Free Maternity Services (FMS) policy is being implemented in Kenya, it is facing challenges from other factors such as availability of staff, inconsistent disbursement of funds to counties, limited supplies and lack of personalized care at facility level. There is an urgent need to review the policy, otherwise quality health care for mothers and their new-borns is at risk.

\section{Context in which FMS policy got implemented in Kenya}

Kenya has an estimated population of 10.8 million aged between 15 and 49 years [3]. Although maternal and child health continues to be one of the strategic priorities in Kenya's health sector, before free maternity services got introduced in 2013 in fulfillment of Kenya's new constitutional demand for universal access to health care, only $44 \%$ of mothers in Kenya were able to access skilled birth attendance (SBA) $[4,5,6]$. The cost of receiving antenatal and delivery services has been observed as one of the barriers that hinder mothers using skilled services in Kenya's public health facilities [7, 8].

Prior to FMS implementation, the Ministry of Health was supposed to employ additional 19,515 nurses and establish 3,091 health facilities in order to meet the national demand for quality maternal services $[9,10]$. Due to resource constraints the government was only able to implement the policy at an estimated cost of $\$ 25-\$ 50$ per mother against the world bank estimated figure of $\$ 148-\$ 170$ per mother for the full cycle of pregnancy including maternity care[11]. The FMS policy was also implemented in a context where public facilities had a perennial history of limited infrastructure; by the time of implementation, only $36 \%$ of public health facilities had the basic minimum requirements to handle deliveries and associated emergencies during deliveries [12].

\section{A cost free policy yet costly on implementation}

\section{Increased workload on service providers}

Implementation of the FMS policy under the devolved health care system in Kenya has seen use of facility based services increase by a range of $50-90 \%$ at county level $[13,14]$. With the increased use of facility services under FMS policy, the number of caesarean sections, referrals and preterm babies also increased (Table 1 \& Figure 1 ) thus putting pressure on the existing human resource for health.

\section{Extra hidden costs to implement FMS}

A couple of surveys that have been carried out show that since implementation of the FMS policy, health facilities are having limited supplies and the county governments have delayed reimbursements from the national government [15]. Further to this the FMS follow-up surveys established that the staff members at facility level are also demotivated by lack of supplies to offer services. This has resulted in mothers being referred to other non-public facilities for diagnostic services at a cost $[16,17]$. All these challenges being experienced are leading to a mismatch in 
Table 1: Trends on type of deliveries in Kenya before and after free maternity care services

\begin{tabular}{|c|c|c|c|c|c|}
\hline Maternal event & $\mathbf{2 0 1 3 / 1 4}$ & $\mathbf{2 0 1 2 / 1 3}$ & $\mathbf{2 0 1 1 / 1 2}$ & $\begin{array}{c}\text { Average change\% from } \\
\mathbf{2 0 1 2 / 1 3} \text { to 2013/14 }\end{array}$ & $\begin{array}{c}\text { Average change \% from } \\
\mathbf{2 0 1 1} / \mathbf{1 2} \text { to 2012/13 }\end{array}$ \\
\hline Normal deliveries & 724,154 & 594,673 & 273,698 & 21.8 & 164.6 \\
\hline Caesarean sections & 104,564 & 89,154 & 41,505 & 17.3 & 151.9 \\
\hline Preterm babies & 23,625 & 18,389 & 11,092 & 28.5 & 113.0 \\
\hline Maternity referrals & 52,908 & 43,723 & 28,120 & 21.0 & 88.2 \\
\hline Neonatal deaths & 9,969 & 7,866 & 4,553 & 26.7 & 119.0 \\
\hline Maternal deaths & 1,006 & 913 & 663 & 10.2 & 51.7 \\
\hline Source; DHIS, 2015 & & & & & \\
\hline
\end{tabular}

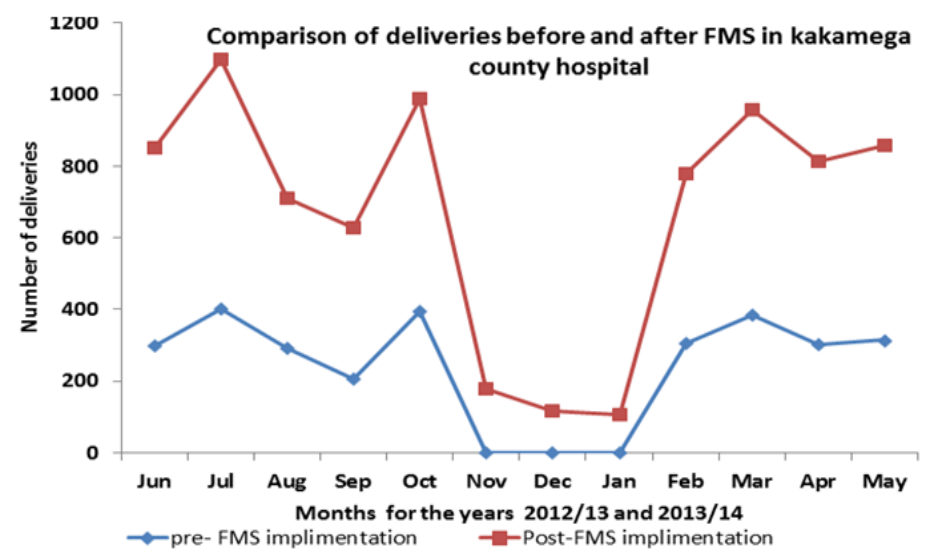

Figure 1: Comparison of deliveries pre and post FMS

Source; Kenyan journal of nursing and midwifery,2016;1:2

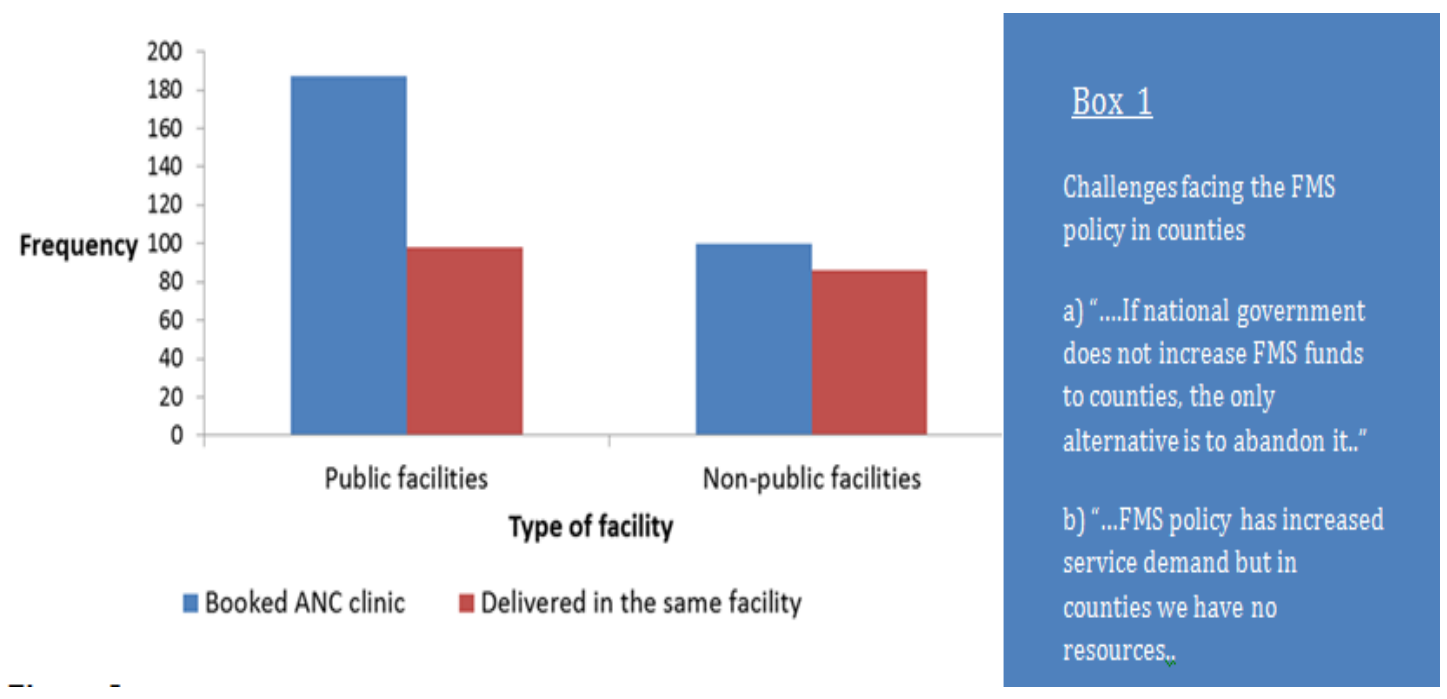

Figure 2: Comparison of ANC and delivery bookings in public and non-public facilities 
the number of mothers who are booked during ANC and those that are booked for deliveries in public health facilities [Figure 2].

\section{Some facilities and counties threatening not to imple- ment FMS policy}

Owing to the levels of frustration at the county level especially from the low reimbursements success rate (50-74\%) by the national government, there are threats from county directors of health to withdraw from subscribing to the policy (Text box $1 \mathrm{a}, \mathrm{b}$ ) [18]. Already some counties have reverted to charging mothers out of pocket fee to meet diagnostic costs especially ultrasound and radiography related diagnostics. Further to this, counties are demanding for increment of FMS policy county funding or else abandon its implementation in totality.

\section{Implications}

The evidence from the Free Maternity Services (FMS) implies that the policy can increase demand for services without necessarily improving pregnancy outcomes. Challenges of facilities having limited supplies for service delivery risk discouraging counties and service providers from implementing FMS policy. If counties revert to charging mothers a user-fee, it might encourage past health seeking behaviors where TBAs were preferred over health facility based caregivers. This will not only increase maternal and new born deaths but will also delay Kenya's achieving of the global targets and national health targets (SDG3 and Kenya's vision 2030).

The high workload under FMS policy that nurses and midwives are handling is likely to cause burn-outs and demotivation among health workers. This might lead to losing of health workers to private sector thus worsening existing shortages in public health facilities. The gains Kenya has made in implementation of the new constitution (article 43,1a) also risk being lost as a result of the challenges facing implementation of the FMS policy.

\section{Possible solutions for the challenges facing FMS policy in Kenya}

For successful and sustainable implementation of the FMS policy in Kenya, there is need to re-engage stakeholders and address various concerns they have regarding the policy. Considering the increased demand for ANC services in public facilities under FMS policy, the national and county governments need to improve on the quantity and quality aspects of service providers. Finally to have healthy mothers and babies in the FMS implementing hospitals, more funding is needed for facilities to obtain various supplies and equipment to meet the increased demand for services.

\section{References}

1. Impact of out of pocket expenditures on families and barriers to use of maternal and child health services in Bangladesh; Findings from the ADB RETA -6515 study.
2. Kenya National Bureau of Statistics (KNBS) and ICF Macro. The Kenya and Demographic Health Survey. 2008-2009. Calverton. Maryland: KNBS and ICF Micro. 2010;

3. Population of women ages 15-49 years. Population Reference Bureau. 2013;

4. Mabel Wakaba, Patrick Mbindyo, Jacob Ochieng, Rose Kiriinya, Jim Todd, Agnes Waudo, et al. The public sector nursing workforce in Kenya: a county -level analysis. Journal of Human Resources for Health. 2014;12:6. Doi: org/10.1186/1478-4491-12-6

5. Government of Kenya, 2010. Health Situation Trends and Distribution 1994-2010 and projections to 2030. MOH, Nairobi.

6. Kibui WA, Mugo KR, Nyaga G, Ngesu LM, Mwaniki IN, Mwaniki B. Health Policies in Kenya and the new constitution for vision 2030. International Journal of Scientific Research and Innovative Technology. 2015;2(1).

7. Mason L, Dellicour S, Kuile FT, Ouma P, Penny PH, Were F, et al. Barriers and facilitators to antenatal and delivery care in western Kenya; a qualitative study. BMC pregnancy and childbirth. 2015;15:26. Doi: org/10.1186/s12884-015-0453-z

8. Fleming E, Gaines J, Oçonnor K, Ogutu J, Atieno N, Kamb ML, et al.. Can incentives reduce barriers to use of antenatal care and delivery of services in Kenya?: Results of a qualitative inquiry. J Health Care Poor Underserved. 2017;28(1):153-174. Doi: 10.1353/hpu.2017.0015

9. Bourbonnais N. Implementing Free Maternal Health care in Kenya; challenges, strategies and recommendations. 2013;

10. The Kenya National Health Sector Strategic and Investment plan; July 2012-June 2018; Nairobi; Ministry of Health.

11. Health Policy paper. Maternal and Child Health Status in Kenya. 2012;

12. Nairobi Act press. Nicole Bourbonnais. Implementation of Free Maternal Healthcare in Kenya's Health Sector Strategic and Investment plan. 2013;

13. Comprehensive assessment report. The Status of implementation of free maternity services (FMS) program in devolved health system in Kenya. Ministry of Health, Nairobi. 2015;

14. Wamalwa EW. Implementation challenges of free maternity services policy in Kenya: the health workers perspective. Pan African journal. 2015;22:375. Doi:10.11604/pamj.2015.22.375.6708

15. Matiang'i M, Karanja S, Wanzala P, Ngure K, Luciani A. The effects of facility related factors on perinatal outcomes- a study of mothers attending antenatal services at public and non-public health facilities in Kisii county in afree maternity care services context. Asian pac J Health Sci. 2017;4(2):183-190. Doi: 10.21276/apjhs.2017.4.2.30

16. Shikely and Khadija Sood Mohamed. Analysis of the effectiveness of free maternity health policy on utilization and financing of health facilities in Mombasa county. 2016;

17. Mukabana B, Arthur K, Theresah W. Effects of the free maternity care program on utilization of services at a county referral hospital in Kenya. Kenyan journal of nursing and midwifery. 2016;1(2):132-144.

18. Murima and John Mwangi. The effect of free maternal health care services on perceived quality of service delivery at Nakuru Provincial General Hospital. Strathmore University. 2016; 